\title{
Measurement of Cyanine Dye Photobleaching in Photosensitizer Cyanine Dye Conjugates Could Help in Optimizing Light Dosimetry for Improved Photodynamic Therapy of Cancer
}

\author{
Nadine S. James ${ }^{1}$, Ravindra R. Cheruku ${ }^{1}$, Joseph R. Missert ${ }^{1}$, Ulas Sunar ${ }^{1,2}$ \\ and Ravindra K. Pandey ${ }^{1, *}$ \\ 1 PDT Center, Cell Stress Biology, Roswell Park Cancer Institute, Buffalo, NY 14263, USA; \\ nadine.james@roswellpark.org (N.S.J.); ravindra.cheruku@roswellpark.org (R.R.C.); \\ joseph.missert@roswellpark.org (J.R.M.); ulas.sunar@roswellpark.org (U.S.) \\ 2 Department of Biomedical Engineering, Wright State University, Dayton, OH 45435, USA \\ * Correspondence: ravindra.pandey@roswellpark.org; Tel.: +1-716-845-3203
}

Received: 24 May 2018; Accepted: 13 July 2018; Published: 24 July 2018

\begin{abstract}
Photodynamic therapy (PDT) of cancer is dependent on three primary components: photosensitizer (PS), light and oxygen. Because these components are interdependent and vary during the dynamic process of PDT, assessing PDT efficacy may not be trivial. Therefore, it has become necessary to develop pre-treatment planning, on-line monitoring and dosimetry strategies during PDT, which become more critical for two or more chromophore systems, for example, PS-CD (Photosensitizer-Cyanine dye) conjugates developed in our laboratory for fluorescence-imaging and PDT of cancer. In this study, we observed a significant impact of variable light dosimetry; (i) high light fluence and fluence rate (light dose: $135 \mathrm{~J} / \mathrm{cm}^{2}$, fluence rate: $75 \mathrm{~mW} / \mathrm{cm}^{2}$ ) and (ii) low light fluence and fluence rate $\left(128 \mathrm{~J} / \mathrm{cm}^{2}\right.$ and $14 \mathrm{~mW} / \mathrm{cm}^{2}$ and $128 \mathrm{~J} / \mathrm{cm}^{2}$ and $\left.7 \mathrm{~mW} / \mathrm{cm}^{2}\right)$ in photobleaching of the individual chromophores of PS-CD conjugates and their long-term tumor response. The fluorescence at the near-infrared (NIR) region of the PS-NIR fluorophore conjugate was assessed intermittently via fluorescence imaging. The loss of fluorescence, photobleaching, caused by singlet oxygen from the PS was mapped continuously during PDT. The tumor responses (BALB/c mice bearing Colon26 tumors) were assessed after PDT by measuring tumor sizes daily. Our results showed distinctive photobleaching kinetics rates between the PS and CD. Interestingly, compared to higher light fluence, the tumors exposed at low light fluence showed reduced photobleaching and enhanced long-term PDT efficacy. The presence of NIR fluorophore in PS-CD conjugates provides an opportunity of fluorescence imaging and monitoring the photobleaching rate of the CD moiety for large and deeply seated tumors and assessing PDT tumor response in real-time.
\end{abstract}

Keywords: Photodynamic therapy; photobleaching; photosensitizers; fluorescence imaging

\section{Introduction}

PDT was initially developed for the local destruction of solid tumors [1,2] and is currently being used worldwide in the treatment of several tumors including skin basal cell carcinoma (BCC) [3], lung [4-6], esophagus [7-11], bladder, head and neck [4,6,12], brain [13-17], ocular melanoma, ovarian, prostate [8-20], renal cell, cervix, pancreas and bone [21]. It is also being used for a plethora of additional indications such as dysplasia, papillomas, rheumatoid arthritis, age related macular degeneration, actinic keratosis, cosmesis, psoriasis, endometrial ablation, localized infection (bacterial and fungal) and prophylaxis of arterial restenosis. Considering that the use of PDT has been approved 
for many diseases, it is still not being practiced in mainstream oncology. In part, this is because the therapy using the light dosimetry based on measured or calculated physical values is not yet optimized.

PDT is known to be dependent on three primary components: Photosensitizer (PS), light and oxygen in order to achieve an effective treatment [1]. Therefore, it is necessary to establish an understanding of the basic physical and biophysical interactions of these three essential components to maximize PDT output. Over the past two decades, much work has been done to optimize these components but their dynamic nature and interdependency lead to complexity. Therefore, a better understanding of PDT dosimetry is important so it will be a reliable tool for controlled enhancement of the therapeutic outcome.

Currently most of the photosensitizers (PS) used in PDT elicit significant damage to cancer cells through singlet oxygen mediated pathways [1]. The standard approach in clinical PDT involves administering a specified amount of photosensitizer (per body weight), wait for a specified time before applying a fixed amount of light $\left\{\right.$ light fluence $\left.\left(\mathrm{J} / \mathrm{cm}^{2}\right)\right\}$ and fluence rate $\{$ total energy delivered within a specific drug-light time interval $\left.\left(\mathrm{mW} / \mathrm{cm}^{2}\right)\right\}$ [22] to treat each patient. However, this approach sometimes leads to incomplete or unpredictable responses in patient groups, which may be due to differences in individual physiological factors [22,23]. These heterogeneous factors include local tissue optical properties, tumor oxygenation and accumulated photosensitizer dose, which can be very different for each patient and tumor. These factors also may change during the PDT treatment. For example, photobleaching of the PS may reduce singlet oxygen production which may cause ground-state oxygen to be depleted if the reperfusion capacity of the tissue is exceeded by the immediate photochemical reaction [24]. Therefore, it has become necessary to develop pretreatment planning, on-line monitoring and dosimetry strategies during PDT [1].

Optimization of clinical dosimetry methods can follow one of three paths as described previously (see for example McIlroy et al. [24], Wilson et al. [25] and Zhu [26]) and can be classified as direct [26], explicit or implicit dosimetry [22,25]. Direct dosimetry involves the measurement of singlet oxygen itself, either through emission of its phosphorescence or through singlet oxygen sensitive chromophores [26]. Explicit dosimetry employs techniques and instrumentation to measure the three essential components of photodynamic therapy (light, photosensitizer (PS) and oxygen) individually and independently in the tissue $[22,25]$. A predictive model of the photobiological effect of these three components is required to combine the measurements into a dose metric $[22,23,25]$. Significant progress has been made in regard to the application of explicit dosimetry but there are still limitations [25]. Implicit dosimetry seeks to avoid measuring the light, PS and oxygen independently by eliciting the use of a single parameter that incorporates two or more of the essential components into a single metric in order to predict the biological damage $[1,22,25,27]$. This is chiefly accomplished by monitoring the PS photobleaching during irradiation by utilizing the fluorescence properties of the PS [22,25].

We are engaged in the exploration of PDT dosimetry strategies by employing the implicit dosimetry approach. In our strategy, we aim to investigate the utility of the photosensitizer-near infrared fluorophores conjugate (PS-NIRF) as fluorescence probes and markers for PDT light dosimetry. We hypothesize that the photobleaching characteristics of the fluorophores when subjected to variable light fluence and fluence rates in treating tumors with variable vascularity will help to optimize the light dosimetry and PDT response.

If singlet oxygen is the main cytoxic agent and the main cause of photobleaching, monitoring the photobleaching could provide a quantifiable measure of the singlet oxygen production. Therefore, we monitored the photobleaching of the photosensitizer and the fluorophore of several bifunctional photosensitizer-fluorophore conjugates using real time in vivo fluorescence imaging. In our initial attempt, the fluorescence of the NIR fluorophore portion of the conjugate was measured intermittently throughout the PDT treatment. First, in vitro photobleaching experiments were performed as a model of the in vivo systems to see if they could predict the in vivo response. Then, we imaged mice before and after PDT treatment at three different light doses, after exciting the PS or the NIRF portion of 
the conjugate individually and investigated potential direct correlation between photobleaching and PDT efficacy.

\section{Results and Discussion}

The degradation of the conjugates was observed via UV-Vis spectroscopy in vitro. Although these solutions of conjugates were made up as $5 \mu \mathrm{M}$ solutions in $17 \%$ Bovine Calf Serum (BCS) it was understood that the intent was not to reproduce exact solvent conditions used clinically but to show whether drug aggregation or binding with serum affected the photobleaching of the chromophores. However, in our in vivo photobleaching experiments the degradation of the NIR fluorophore (CD) portion of the PS-CD conjugates was observed. In later experiments, we observed the degradation of both PS and CD via fluorescence quenching.

\subsection{Mechanism of Photo-Induced Bleaching}

Using the NIR CD as a guide, Figure 1, illustrates the mechanism of photo-degradation caused by the contribution of molecular oxygen and light. Interaction of singlet oxygen with the chromophores constitutes the major pathway of photodecomposition. When the PS (HPPH) portion of the PS-NIR fluorophore (CD) conjugate absorbs light it undergoes intersystem crossing from an excited singlet state to an excited triplet state where it interacts with endogenous ground state triplet oxygen to generate the destructive singlet oxygen species. In the illustration below, the singlet oxygen generated subsequently attacks the polymethine chain of cypate resulting in fragmentation of the CD moiety as shown in Figure 1.
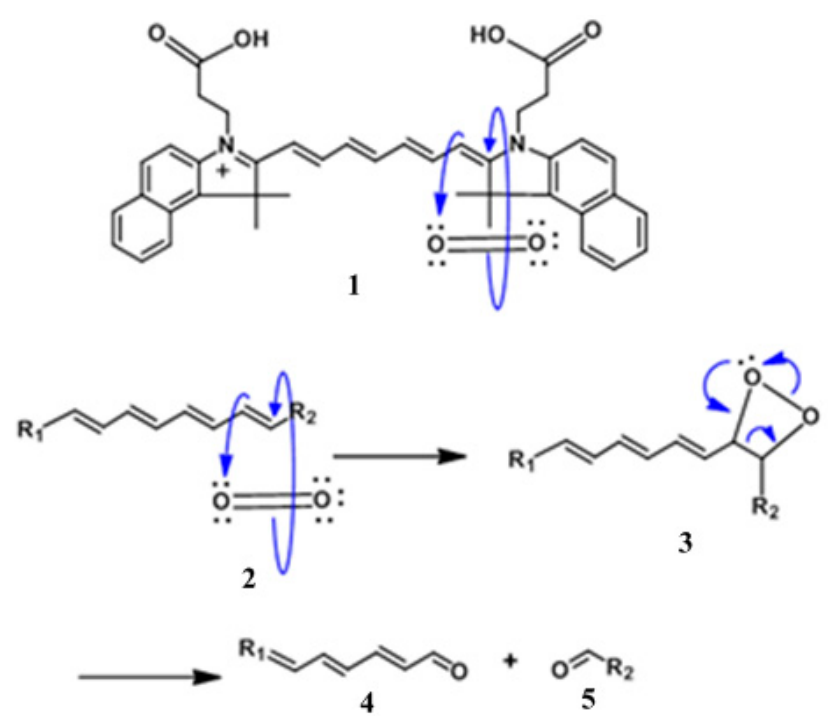

Figure 1. Mechanism of the photobleaching of Cypate by singlet oxygen. This illustrates the photobleaching that occurs in vitro and in vivo following absorbance of light in the near-infrared (NIR) region of the spectrum.

The photoproduct obtained after photo-induced bleaching is due to oxidation of the $\mathrm{C}^{\prime}-\mathrm{C} 2$ or $\mathrm{C}^{\prime}-\mathrm{C} 2$ " bond on the polymethine chain. Singlet oxygen is directed towards the polymethine chain at the $\mathrm{C}^{\prime}-\mathrm{C} 2$ or $\mathrm{C}^{\prime}-\mathrm{C} 2^{\prime \prime}$ bond due the electro-positivity of the 2 and 2" carbon versus the electron rich position $1^{\prime}$ or $7^{\prime}$ of the cationic chromophore [28]. This degradation generates the corresponding carbonyl photoproducts [28]. 


\subsection{In Vitro Photobleaching of HPPH Cyanine Dye and CD Conjugates}

The conjugates: HPPH-CD (8), $\mathrm{HPPH}_{2}-\mathrm{CD}(\mathbf{9}), \mathrm{HPPH}-\mathrm{Cypate}(\mathbf{1 0})$ and $\mathrm{HPPH}_{2}-\mathrm{Cypate}(\mathbf{1 1})$ shown in Figure 2 prepared by following our own methodology [29,30] were formulated in 17\% Bovine Calf Serum/PBS and were used at equimolar concentrations $(5 \mu \mathrm{M})$. The absorption spectra were measured in $1 \mathrm{~cm}$-quartz cuvettes following irradiation at $661 \mathrm{~nm}$ (light dose: $\left.135 \mathrm{~J} / \mathrm{cm}^{2}, 75 \mathrm{~mW} / \mathrm{cm}\right)^{2}$ at various time points until there was nearly complete degradation of the NIRF portion of the conjugate (Figure 3 ).
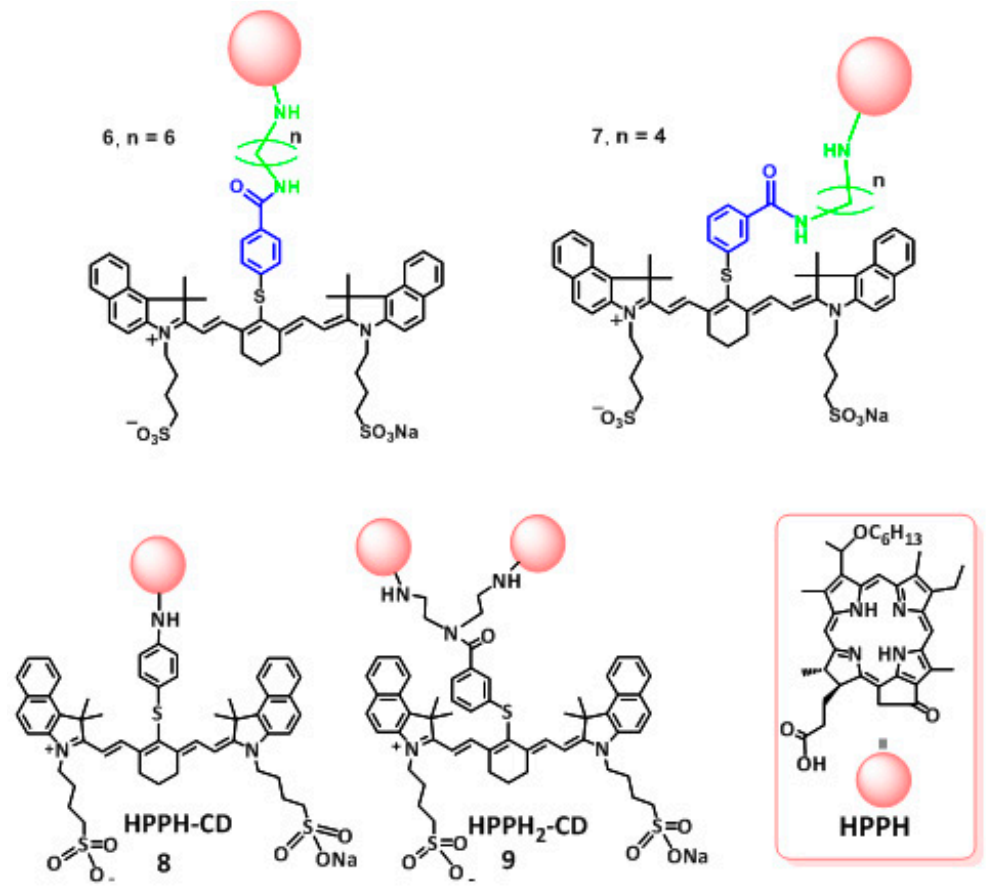

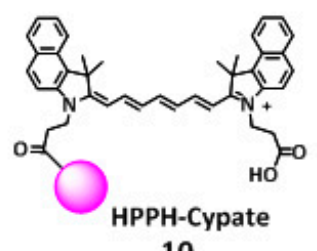

10

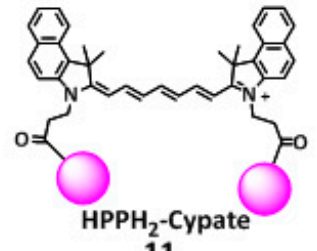

11

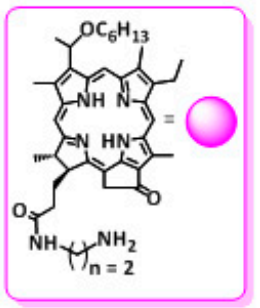

Figure 2. Structures of the conjugates 6-11 used for the study.
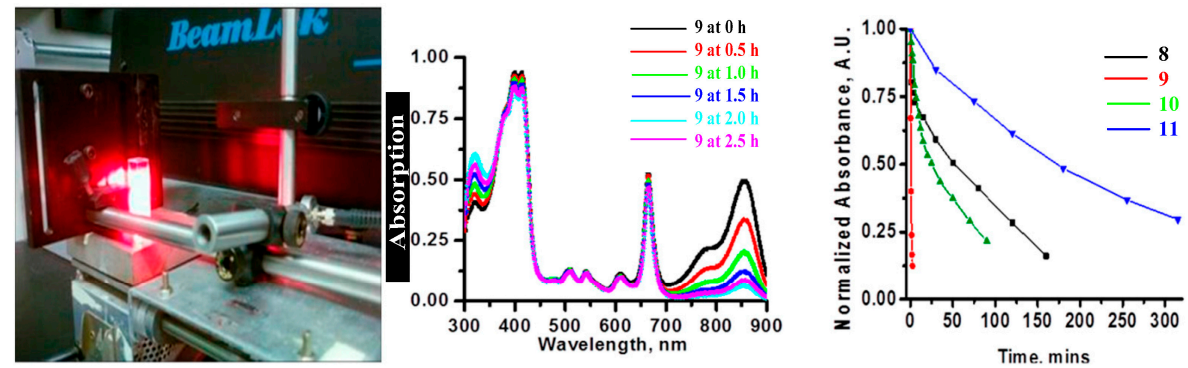

Figure 3. In vitro photobleaching rates of the conjugates at $5 \mu \mathrm{M}$ solutions in $17 \%$ bovine calf serum (BCS) in phosphate buffer saline (PBS). HPPH-CD (8), $\mathrm{HPPH}_{2}-\mathrm{CD}$ (9), HPPH-Cypate (10) and $\mathrm{HPPH}_{2}$-Cypate (11) were in the order of $\mathbf{9}>\mathbf{1 0}>\mathbf{8}>\mathbf{1 1}$. The rate of photobleaching of the chromophores was determined on the basis of reduced absorption at $661 \mathrm{~nm}(\mathrm{HPPH})$ and near $830 \mathrm{~nm}$ cyanine dye (CD) after irradiating with light $\left(135 \mathrm{~J} / \mathrm{cm}^{2}, 75 \mathrm{~mW} / \mathrm{cm}^{2}\right)$ at $661 \mathrm{~nm}$ (in vitro absorption wavelength). 


\subsection{In Vivo Photo-Induced Bleaching Kinetics}

BALB/c mice (3/group) were inoculated with compounds 8, 9, 10 and 11 and monitored during PDT for $30 \mathrm{~min}$ at various time intervals. The tumors were irradiated at a wavelength $665 \mathrm{~nm}$ using a total light dose of $135 \mathrm{~J} / \mathrm{cm}^{2}$ and fluence rate of $75 \mathrm{~mW} / \mathrm{cm}^{2}$, respectively. Concurrently, the fluorescence kinetics were monitored by illuminating at $785 \mathrm{~nm}$ and measuring the fluorescence with an 830 long pass filter. Figure 3 shows images of the photo-induced bleaching kinetics of the four conjugates 8, 9, 10 and 11 at different time points during treatment. The mice injected with HPPH-Cypate (10) were irradiated at $665 \mathrm{~nm}$. PDT efficacy of HPPH-CD (8), HPPH2CD (9), HPPH-Cypate (10) and HPPH2-Cypate (11) was also assessed after the photo-induced bleaching experiment, as shown in Figure 4. We observed that there were no PDT cures upon assessment of the tumor response (Figures 4 and 5). All mice were sacrificed when the tumor sizes grew to a volume of $400 \mathrm{~mm}^{3}$. The dismal tumor response could be due to changes in tumor oxygenation induced by high fluence rates [31]. High fluence rates such as that used in this experiment $\left(135 \mathrm{~J} / \mathrm{cm}^{2}\right.$ and $\left.75 \mathrm{~mW} / \mathrm{cm}^{2}\right)$ can cause the depletion of molecular oxygen during the process of singlet oxygen generation, which can exceed the rate at which it can be resupplied by diffusion from the vasculature [31].
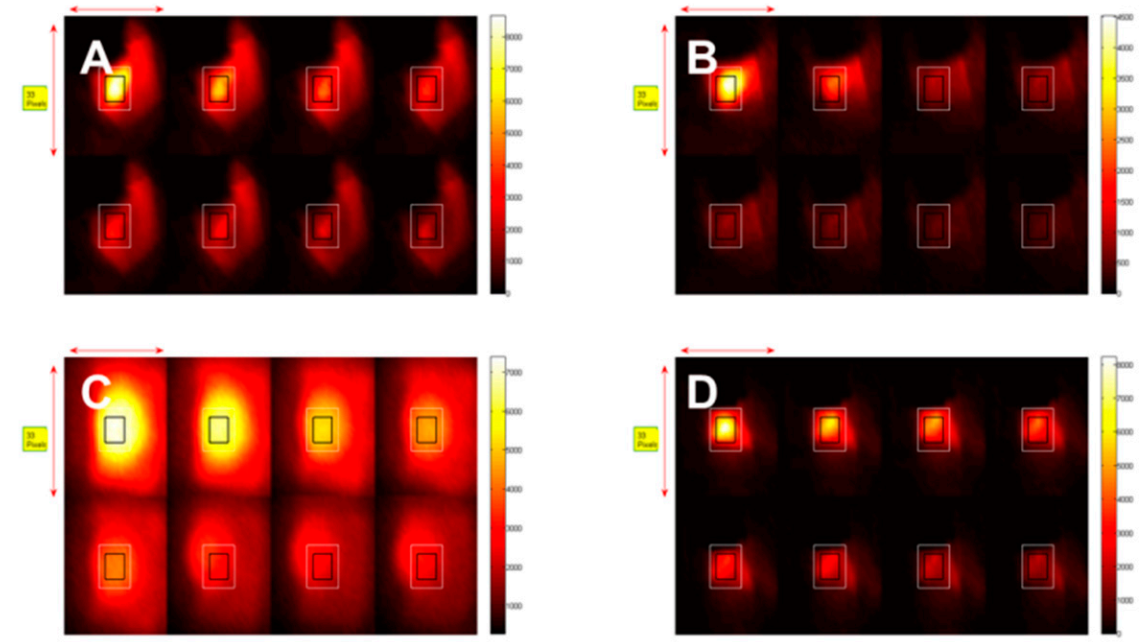

Figure 4. In vivo photobleaching of the $\mathrm{CD}$ in (A) HPPH-CD (8), (B) $\mathrm{HPPH}_{2}-\mathrm{CD}(9)$, (C) $\mathrm{HPPH}-\mathrm{Cypate}$ (10) and (D) $\mathrm{HPPH}_{2}$-Cypate (11) conjugates in Colon26 tumors implanted in BALB/c mice. All conjugates were irradiated at $665 \mathrm{~nm}$, after $24 \mathrm{~h}$ post-injection and treated at a fluence and fluence rate of $135 \mathrm{~J} / \mathrm{cm}^{2}$ and $75 \mathrm{~mW} / \mathrm{cm}^{2}$. Concurrently fluorescence images were taken (wavelength detection $>830 \mathrm{~nm}$ ) at various treatment times up to $30 \mathrm{~min}$, the total treatment time.

The difference in the rate of in vitro versus in vivo photobleaching could be due to inability of our system to exclude environmental oxygen during the light irradiation and measuring the absorption spectra at various time points, whereas under in vivo conditions, the amount of available oxygen in restricted (it could vary in tumor types). It is believed that such occurrences would lead to PDT self-limiting hypoxic conditions [31] whereby the tumor and surrounding regions become deprived of oxygen. Therefore, we adapted the following experiments with the low-fluence rates. However, for this study, besides 9 (which showed limited in vivo PDT efficacy, Figure 5), we also selected conjugates 6, 7 and 12. In our previous study 6 and 7 showed improved long-term cure over 12 at higher light fluence $\left(135 \mathrm{~J} / \mathrm{cm}^{2}\right)$ and fluence rate $\left(75 \mathrm{~mW} / \mathrm{cm}^{2}\right)[29,30]$. The other reason, for the selection of these conjugates was to understand the impact of the length of linkers between the two chromophores as well as the number of HPPH moiety. 

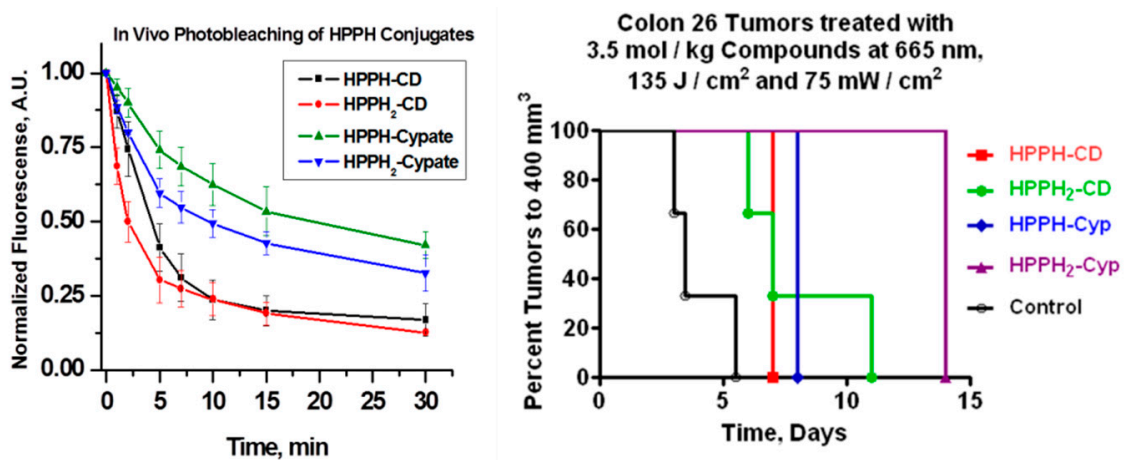

Figure 5. In vivo photobleaching of the conjugates: $\mathrm{HPPH}-\mathrm{CD} 8, \mathrm{HPPH}_{2}-\mathrm{CD}$ 9, $\mathrm{HPPH}-\mathrm{Cypate} 10$ and $\mathrm{HPPH}_{2}$-Cypate $\mathbf{1 1}$ occurred in the order of $\mathbf{9}>\mathbf{8}>\mathbf{1 1}>\mathbf{1 0}$. There were no photodynamic therapy (PDT) cures upon assessment of the tumor response (the tumors were irradiated with light (Figure 4) at $24 \mathrm{~h}$ post-injection). The tumor growth was measured daily, when the tumors reached to a volume of $>400 \mathrm{~mm}^{3}$, the mice were euthanized following the approved IACUC protocol. Control: The tumored mice were intravenously (i.v.) injected with the PS but the tumors were not exposed to light.

\subsection{In Vivo Photobleaching before and after Low Fluence Light Treatments}

It has been demonstrated that there was a direct relationship between the tumor response and the level of oxygen within the tumor tissue during PDT [31-38]. Additionally, it has also been demonstrated that using HPPH as a PS and exposing the tumor at low light fluence and fluence rate of $128 \mathrm{~J} / \mathrm{cm}^{2}$ and $14 \mathrm{~mW} / \mathrm{cm}^{2}$ showed better tumor response rates with cures up 90 days after PDT [31,33]. Another observation made during these experiments was that the tumor response for the fluence of $128 \mathrm{~J} / \mathrm{cm}^{2}$ increased as the fluence rate decreased further [31,33]. Therefore, to understand the impact of these light treatment parameters in PDT efficacy of the PS-CD conjugates, the photobleaching experiments were conducted at various fluence and fluence rates of $135 \mathrm{~J} / \mathrm{cm}^{2}$ and $75 \mathrm{~mW} / \mathrm{cm}^{2} ; 128 \mathrm{~J} / \mathrm{cm}^{2}$ and $14 \mathrm{~mW} / \mathrm{cm}^{2}$ and $128 \mathrm{~J} / \mathrm{cm}^{2}$ and $7 \mathrm{~mW} / \mathrm{cm}^{2}$ (Figure 6).

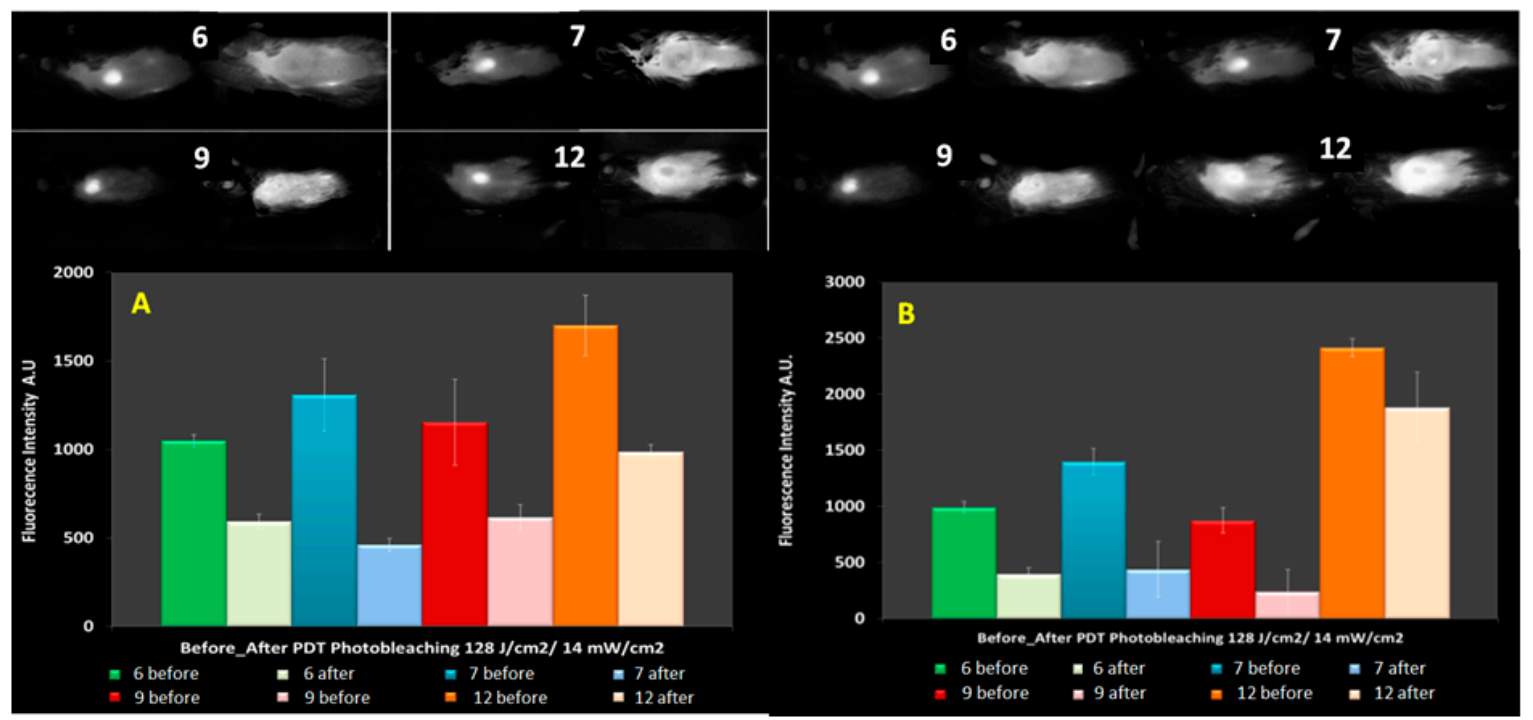

Figure 6. (A) Photobleaching of the HPPH portion of PS-CD conjugates and (B) a comparative photobleaching of the CD moiety in HPPH-CD conjugates 6, 7, 9 and 12 at the light dose of $128 \mathrm{~J} / \mathrm{cm}^{2}$ and $14 \mathrm{~mW} / \mathrm{cm}^{2}$.

In these experiments, the fluorescence was observed before and after PDT treatment at the fluence and fluence rates mentioned above. The compounds chosen for this study were conjugates 6, 7, 9 
(Figure 2) and 12 (Figure 7) on the basis of their significant in vitro and in vivo PDT responses in mice bearing Colon-26 and U87 tumor models [29,30]. The photobleaching data obtained from these experiments were used in conjunction with the molecular modeling of the compounds to infer possible optimization of PDT light dosimetry since it has been reported that it is not simple to predict the photobiological outcome from in vivo photobleaching data alone, because of the complex dependence on oxygenation and micro-environment factors [22]. The fluorescence of HPPH and the CD were also compared prior to light irradiation and at the end of treatment with light dose of $128 \mathrm{~J} / \mathrm{cm}^{2}$ and $14 \mathrm{~mW} / \mathrm{cm}^{2}$. After combining the data obtained from the three mice in each group it was found that the HPPH (PS) portion of compounds 6, 7, 9 and 12 photobleached by 43\%, 65\%, 47\% and 42\% respectively; whereas, the CD portion underwent photobleaching by $60 \%, 69 \%, 73 \%$ and $22 \%$ respectively.

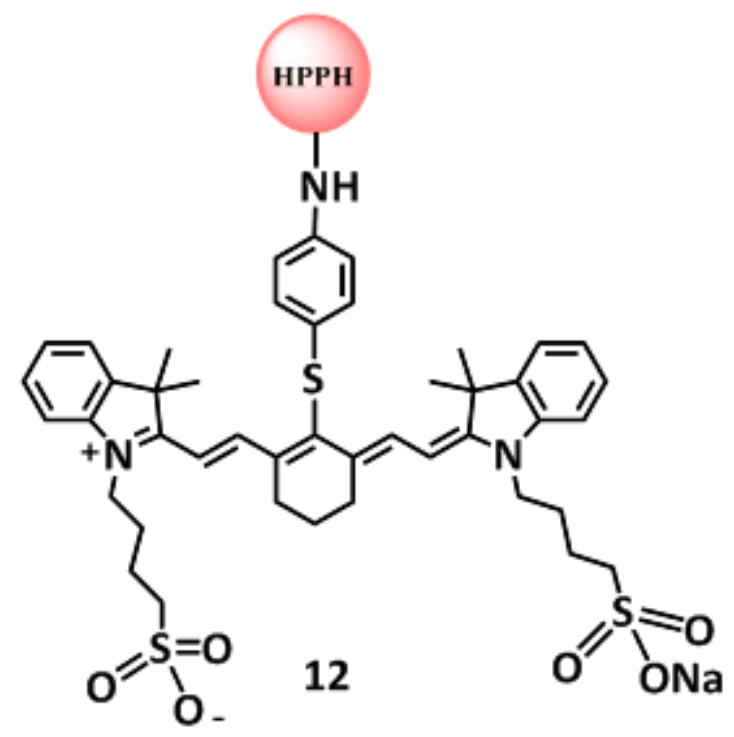

Figure 7. Structure of HPPH-CD conjugate 12.

Under similar treatment parameters, the photobleaching rates of the CD portion of the conjugate in 6, 7 and 9 were observed in the range of $60-73 \%$ when irradiated at $128 \mathrm{~J} / \mathrm{cm}^{2}$ and $14 \mathrm{~mW} / \mathrm{cm}^{2}$. On the other hand, the PDT response was $40 \%$ for conjugate 9 with only $20 \%$ photobleaching observed for the CD (Table 1). These results suggest that there is a direct correlation between the rate of photobleaching of the CD and the tumor response; more the photobleaching of the CD in HPPH-CD conjugates, the higher was the tumor response. It was difficult to infer a similar conclusion in the case of HPPH photobleaching with respect to tumor response, since the photobleaching rates were quite similar for all the cases except compound 6. Summary of photobleaching rates of 6, 7, 9 and 12 at $128 \mathrm{~J} / \mathrm{cm}^{2}$ and $14 \mathrm{~mW} / \mathrm{cm}^{2}$ are shown in Tables 1 and 2.

There was no PDT response when a fluence and fluence rate of $128 \mathrm{~J} / \mathrm{cm}^{2}$ and $7 \mathrm{~mW} / \mathrm{cm}^{2}$ was used. This can be explained by the threshold dose below which the repair of sub-lethal damage overrides the advantages of low fluence rate $[31,39,40]$. However, in the experiment where fluence rates of $135 \mathrm{~J} / \mathrm{cm}^{2}$ and $75 \mathrm{~mW} / \mathrm{cm}^{2}$ (Table 3) were used, the photo-induced bleaching of the CD portion of the conjugate was between $16 \%$ and $52 \%$ and there was a tumor response of $66 \%$ and $33 \%$ for compounds 9 and 12 , respectively. The degree of photobleaching of the HPPH moiety also correlated well with the NIRF moiety. Therefore, the less photobleached the HPPH or NIRF at $135 \mathrm{~J} / \mathrm{cm}^{2}$ and $75 \mathrm{~mW} / \mathrm{cm}^{2}$ the better was the response. This could also be due to with the amount accumulated conjugate (PS) within the tumor before PDT light illumination. It has been shown that the combination of fluence and fluence rate can lead to anoxic conditions within the first few minutes of illumination [31,33]. Therefore, it can be deduced that if the amount of photosensitizer accumulated within the tumor prior to PDT is high this would help to circumvent the observance of anoxic conditions. 
Table 1. Summary of a comparative in vivo photobleaching of HPPH moiety in HPPH-CD conjugates 6, 7, 9 and 12 after the light treatment $\left(128 \mathrm{~J} / \mathrm{cm}^{2}\right.$ and 14 $\mathrm{mW} / \mathrm{cm}^{2}$ ) for $30 \mathrm{~min}$. The tumors were exposed to light at $665 \mathrm{~nm}$ (in vivo absorption of HPPH at its longest wavelength absorption) after $24 \mathrm{~h}$ post-injection of the conjugates.

\begin{tabular}{|c|c|c|c|c|c|c|c|c|}
\hline \multicolumn{2}{|c|}{ Compounds } & \multicolumn{4}{|c|}{ Fluorescence (Not an Absolute Value) } & \multicolumn{2}{|c|}{ Photobleached $128 \mathrm{~J} / \mathrm{cm}^{2} 14 \mathrm{~mW} / \mathrm{cm}^{2}$} & \multirow{2}{*}{$\begin{array}{c}\% \text { Tumor Cured } 128 \mathrm{~J} / \mathrm{cm}^{2} 14 \mathrm{~mW} / \mathrm{cm}^{2} \\
\text { PDT ONLY }\end{array}$} \\
\hline Drug\# & Dose $(\mu \mathrm{mol} / \mathrm{kg})$ & Pre PDT HPPH & Pre PDT CD & Post PDT HPPH & Post PDT CD & \% HPPH Photo-Bleached & $\%$ CD Photo-Bleached & \\
\hline 6 & 1.5 & 1048 & 989 & 592 & 397 & 43 & 60 & 80 \\
\hline 7 & 1.5 & 1308 & 1396 & 460 & 439 & 65 & 69 & 80 \\
\hline 9 & 1.5 & 1154 & 874 & 616 & 239 & 47 & 73 & 80 \\
\hline 12 & 1.5 & 1701 & 2413 & 986 & 1881 & 42 & 22 & 40 \\
\hline
\end{tabular}

Table 2. Summary of the photobleaching results with conjugates $6,7,9$ and 12 at a light dose of $48 \mathrm{~J} / \mathrm{cm}^{2}$ and $7 \mathrm{~mW} / \mathrm{cm}^{2}$. The PDT activity of the conjugates at a light dose of $48 \mathrm{~J} / \mathrm{cm}^{2}, 7 \mathrm{~mW} / \mathrm{cm}^{2}$ was not determined (ND).

\begin{tabular}{|c|c|c|c|c|c|c|c|c|}
\hline \multicolumn{2}{|c|}{ Compounds } & \multicolumn{4}{|c|}{ Fluorescence (Not an Absolute Value) } & \multicolumn{2}{|c|}{ Photobleached $48 \mathrm{~J} / \mathrm{cm}^{2} 7 \mathrm{~mW} / \mathrm{cm}^{2}$} & \multirow{2}{*}{$\begin{array}{c}\% \text { Tumor Cured } 48 \mathrm{~J} / \mathrm{cm}^{2} 7 \mathrm{~mW} / \mathrm{cm}^{2} \\
\text { PDT ONLY }\end{array}$} \\
\hline Drug\# & Dose $(\mu \mathrm{mol} / \mathrm{kg})$ & Pre PDT HPPH & Pre PDT CD & Post PDT HPPH & Post PDT CD & \% HPPH Photo-Bleached & \% CD Photo-Bleached & \\
\hline 6 & 1.5 & 1060 & 976 & 825 & 492 & 22 & 50 & ND \\
\hline 7 & 1.5 & 1485 & 1319 & 1170 & 1019 & 21 & 23 & ND \\
\hline 9 & 1.5 & 986 & 809 & 808 & 459 & 18 & 43 & ND \\
\hline 12 & 1.5 & 1428 & 2538 & 1238 & 1783 & 13 & 30 & ND \\
\hline
\end{tabular}

Table 3. Summary of the photobleaching of conjugates $6,7,9$ and 12 at $135 \mathrm{~J} / \mathrm{cm}^{2}$ and $75 \mathrm{~mW} / \mathrm{cm}^{2}$.

\begin{tabular}{|c|c|c|c|c|c|c|c|c|}
\hline \multicolumn{2}{|c|}{ Compounds } & \multicolumn{4}{|c|}{ Fluorescence (Not an Absolute Value) } & \multicolumn{2}{|c|}{ Photobleached $135 \mathrm{~J} / \mathrm{cm}^{2} 75 \mathrm{~mW} / \mathrm{cm}^{2}$} & \multirow{2}{*}{$\begin{array}{c}\% \text { Tumor Cured } 135 \mathrm{~J} / \mathrm{cm}^{2} 75 \mathrm{~mW} / \mathrm{cm}^{2} \\
\% \text { Tumor Cure }\end{array}$} \\
\hline Drug\# & Dose $(\mu \mathrm{mol} / \mathrm{kg})$ & Pre PDT HPPH & Pre PDT CD & Post PDT HPPH & Post PDT CD & \% HPPH Photo-Bleached & \% CD Photo-Bleached & \\
\hline 6 & 1.5 & 1136 & 1025 & 670 & 416 & 41 & 60 & 0 \\
\hline 7 & 1.5 & 1380 & 1319 & 655 & 560 & 53 & 58 & 0 \\
\hline 9 & 1.5 & 996 & 904 & 683 & 430 & 31 & 52 & 33 \\
\hline 12 & 1.5 & 1392 & 2543 & 1390 & 2143 & 8 & 16 & 66 \\
\hline
\end{tabular}




\section{Experimental:}

(a) Chemistry: Compounds investigated in this study were synthesized and characterized by following our own methodology $[29,30]$.

(b) Photophysical characterization: UV-vis absorption spectra were acquired using a Shimadzu UV-3600 spectrophotometer. Fluorescence spectra were recorded using a Fluorolog-3spectrofluorometer or a SPEX 270M Spectrometer (Jobin Yvon, Longjumeau, France). The SPEX 270 M Spectrometer was utilized for measurement in NIR range; laser lines from Argon ion laser (Spectra Physics) or laser diodes emitting at $630 \mathrm{~nm}$ and $785 \mathrm{~nm}$ was used as excitation wavelength and the emission was recorded (Tables 1-3).

(c) In vitro and in vivo photobleaching: In vitro photobleaching was conducted by observing the UV-vis spectra of conjugates at $5 \mu \mathrm{M}$ concentrations dissolved either in methanol or in $1 \%$ Tween 80 formulation diluted with methanol (30-fold, for complete disaggregation of the product). The solution of conjugate in cuvette was then irradiated with light (therapeutic light dose) at various time points for $30 \mathrm{~min}$. At these time intervals, the UV-vis spectrum was taken and the rate of photobleaching (decrease of absorption intensity) at the longest wavelength absorptions of the PS and CD moieties present in PS-CD conjugates were measured and plotted against time. To determine the rate of in vivo photobleaching of the PS and CD moieties during the PDT BALB/c mice (5 mice/group) bearing Colon26 tumors were injected (i.v.) with the conjugate(s) and at $24 \mathrm{~h}$ post injection (the time point for maximal uptake of the compound). Three sets of therapeutic light doses (light fluence and fluence rates) used for this study were: $\left(135 \mathrm{~J} / \mathrm{cm}^{2}\right.$, $\left.\left.128 \mathrm{~J} / \mathrm{cm}^{2}\right), 128 \mathrm{~J} / \mathrm{cm}^{2}, 14 \mathrm{~mW} / \mathrm{cm}^{2}\right)$ and $\left(48 \mathrm{~J} / \mathrm{cm}^{2}, 7 \mathrm{~mW} / \mathrm{cm}^{2}\right)$. The fluorescence intensity was measured using the RED (615-665 nm; $750 \mathrm{~nm}$ long-pass) and NIR (710-760 nm; $800 \mathrm{~nm}$ long pass) excitation and emission before and after PDT for the PS and CD moieties respectively. These experiments were performed using the drug dose of $1.5 \mu \mathrm{mol} / \mathrm{kg}$ for all the conjugates.

(d) In vivo PDT efficacy: Prior to commencement of in vivo studies, all procedures or protocols were approved by the institutional animal care committee (IACUC). In brief, BALB/c mice 5-8 weeks of age were obtained from NCI Jackson Laboratory. The mice were inoculated subcutaneously (S. C.) on the right posterior shoulder with Colon-26 $\left(1 \times 10^{6}\right.$ cells in $50 \mu \mathrm{L}$ medium $)$ between 7 and 14 weeks of age. The tumors reaching the appropriate treatment size (4-5 mm diameter), the mice were injected with the conjugate intravenously (i.v.) via tail vein injection. At $24 \mathrm{~h}$ post injection, the mice were restrained in plexiglass holders without anesthesia, treated with a $1.1 \mathrm{~cm}$ diameter area of drug-activating laser light at $665 \mathrm{~nm}$ at different light fluence and fluence rates (Tables 1 and 2). The mice were observed daily for tumor re-growth and tumor cure. Upon tumor recurrence measurements were taken using two orthogonal measurements length and width (perpendicular to L); volumes of tumors were calculated using the Microsoft Excel formula $\mathrm{V}=\mathrm{L}^{*} \mathrm{~W}^{2} / 2$ and recorded. Mice were considered cured if there was no palpable tumor by day 60; however, if the tumor reached $400 \mathrm{~mm}$ in size they were euthanized.

(e) Tumor imaging: BALB/c mice bearing Colon-26 tumors (3 mice/group) were injected (i.v.) with the conjugate (s) and imaged at three time points 24,48 and $72 \mathrm{~h}$ after being anesthetized with Ketamine/Xylazine, delivered intraperitoneally or anesthetized with isoflurane. Compounds were imaged using a Maestro GNIR Flex in vivo imaging system using a broadband excitation at $710-740 \mathrm{~nm}$ and $800 \mathrm{~nm}$ long pass emission.

\section{Conclusions}

The data acquired from the in vitro photo-induced bleaching of conjugates showed that NIR fluorophore $\mathrm{CD}$ of the conjugates photobleached at a much faster rate than HPPH and the rate of bleaching was in the order of $\mathbf{9}>\mathbf{1 0}>\mathbf{8}>\mathbf{1 1}$, which correlated well with their in vivo PDT responses when irradiated at $128 \mathrm{~J} / \mathrm{cm}^{2}$ and $14 \mathrm{~mW} / \mathrm{cm}^{2}$, using a drug dose of $1.5 \mu \mathrm{mol} / \mathrm{kg}$. Conjugate 12 produced $80 \%$ tumor response, whereas compounds 10 and 11 did not yield any long-term cure. 
The in vivo photobleaching of HPPH and CD in conjugates before and after PDT suggests that measuring the rate of the photobleaching of $C D$ could be a useful tool to optimize the PDT light dosimetry. We hypothesize that the determining the rate of photobleaching of CD in PS-CD conjugates may help to measure indirectly the amount of singlet oxygen generation during photodynamic therapy treatment at variable light fluence and fluence rates $[1,22]$. These studies are currently underway. A decreased rate of photobleaching of HPPH over the CD in HPPH-CD conjugates could be due to higher reactivity of singlet oxygen to polymethine linkers present in the $\mathrm{CD}$ moiety as shown in Figure 1.

According to Wilson et al. [41] the use of photobleaching as a dose metric is based on the fact that the photosensitizer or NIR fluorophore will be degraded directly or indirectly by singlet oxygen as it goes through each photo-activation cycle [41]. An enhanced level of photo-activation is directly proportional to enhanced photobleaching. As a result, a hypothesis is proposed that greater photobleaching represents greater singlet oxygen production and hence an enhanced photodynamic efficacy [41]. However, this assumption/hypothesis may lead to several issues such as: (i) If the fluorescence of the PS is used for the measurements without knowing the absolute initial concentration of the PS, it could be difficult to determine the absolute number of PS molecules photobleached per unit volume during PDT [39]. It has been shown, however, that this requirement can be fulfilled by quantitative fluorescence imaging methods that can quantify absolute PS concentrations (ii) Molecular changes of the PS within tissue may result in changes to the fluorescence without any changes in PDT response [41]; (iii) the photobleaching rate itself may not be a sole indicator for PDT dosimetry/response [41], since it has been shown that singlet oxygen generation is dependent on the tissue microenvironment [4,41]. The micro/local-distribution of the PS will be difficult to quantify because noninvasive or noninvasive fluorescence measurements are limited and can only provide a measure of average/bulk value of the PS concentration.

We agree with the comments of one of the reviewers: "The goal of this study was to ascertain if there was a quantitative relation between photobleaching of the PS and PDT activity. Though that goal was not attained, a semi-quantitative relation between the rate of photobleaching of the CD in HPPH-CD conjugates and various light fluence and fluence rates suggests that this approach with further refinements could be useful for clinicians in identifying the location of the tumors by fluorescence imaging $>830 \mathrm{~nm}$ and the depletion of oxygen during the PDT treatment measured by photobleaching of the CD." These studies with these and other PS-CD conjugates are currently in progress.

Author Contributions: N.S.J.: Synthesis of the conjugates and biological evaluation (in vitro, in vivo) evaluation of the compounds. N.S.J. also prepared the first draft of the manuscript. R.R.C.: Synthesized some of the PS-CD conjugates required to confirm the photophysical properties. J.R.M.: Isolated the starting material from Spirulina pacifica, which mainly contains chlorophyll-a. U.S.: Designed the in vivo photobleaching experiments, helped in analyzing the data and also providing helpful comments on the manuscript. R.K.P.: Overall supervision of the project including the design of the conjugates studied in this project, providing financial assistance from the NIH funded grant in which he is the PI and refining the manuscript before submission.

Funding: The research was funded by the NIH.

Acknowledgments: The authors are thankful to NIH for the financial support: RO1 CA127369 (RKP) and research supplement to promote diversity in health-related research to Nadine S. James (CA127369S). This work utilized core resources supported by the NCI Cancer Center Support Grant CA016156 (Johnson: PI).

Conflicts of Interest: The authors declare no conflict of interest.

\section{References}

1. Li, B.; Lin, L.; Lin, H.; Wilson, B.C. Photosensitized singlet oxygen generation and detection: Recent advances and future perspectives in cancer photodynamic therapy. J. Biophotonics 2016, 9, 1314-1325. [CrossRef] [PubMed]

2. Sanchez-Barcelo, E.J.; Mediavilla, M.D. Recent patents on light based therapies: Photodynamic therapy, photothermal therapy and photoimmunotherapy. Phys. Med. Biol. 2014, 8, 1-8. [CrossRef] 
3. Ozog, D.M.; Rkein, A.M.; Fabi, S.G.; Gold, M.H.; Goldman, M.P.; Lowe, N.J.; Martin, G.M.; Munavalli, G.S. Photodynamic Therapy: A Clinical Consensus Guide. Dermatol. Surg. 2016, 42, 804-827. [CrossRef] [PubMed]

4. $\quad$ Francisco, J.C.; Barış, K.M.; Biel, C.E.; Alessandra, S.R.F.; Saba, R.P. Takes Vincent Vander PoortenAlfio Ferlito. A Review of Photodynamic Therapy for Neoplasms of the Head and Neck. Adv. Ther. 2018, 35, 324-340.

5. Shafirstein, G.; Battoo, A.; Harris, K.; Baumann, H.; Gollnick, S.O.; Lindenmann, J.; Nwogu, C.E. Photodynamic Therapy of Non-Small Cell Lung Cancer. Narrative Review and Future Directions. Ann. Am. Thorac. Soc. 2016, 13, 265-275. [CrossRef] [PubMed]

6. Nwogu, C.; Pera, P.; Bshara, W.; Attwood, K.; Pandey, R. Photodynamic therapy of human lung cancer xenografts in mice. J. Surg. Res. 2016, 200, 8-12. [CrossRef] [PubMed]

7. Davila, M.L. Photodynamic therapy. Gastrointest. Endosc. Clin. N. Am. 2011, 21, 67-79. [CrossRef] [PubMed]

8. Duvanskii, V.A.; Kniazev, M.V.; Pravednikov, P.V. Modern aspects of photodynamic therapy of esophageal. Eksp. Klin. Gastroenterol. 2011, 10, 111-116.

9. Fiorelli, A.; Prencipe, A.; Santini, M. The renaissance of photodynamic therapy for early esophageal cancer: Is it the time? J. Thorac. Dis. 2018, 10 (Suppl. 9), S1013-S1015. [CrossRef] [PubMed]

10. Straten, V.D.; Mashayekhi, V.; de Bruijn, H.S.; Oliveira, S.; Robinson, D.J. Oncologic Photodynamic Therapy: Basic principles, current clinical status and future directions. Cancers 2017, 18, 19. [CrossRef] [PubMed]

11. Shishkova, N.; Kuznetsova, O.; Berezov, T. Photodynamic therapy in gastroenterology. J. Gastrointest. Cancer 2013, 44, 251-259. [CrossRef] [PubMed]

12. Nelke, K.H.; Pawlak, W.; Leszczyszyn, J.; Gerber, H. Photodynamic therapy in head and neck cancer. Postepy Hig. Med. Dosw. (Online) 2014, 68, 119-128. [CrossRef] [PubMed]

13. Dobson, J.; de Queiroz, G.F.; Golding, J.P. Photodynamic therapy and diagnosis: Principles and comparative aspects. Vet. J. 2018, 233, 8-18. [CrossRef] [PubMed]

14. Wen, P.Y.; Omuro, A.; Ahluwalia, M.S.; Fathallah-Shaykh, H.M.; Mohile, N.; Lager, J.J.; Laird, A.D.; Tang, J.; Jiang, J.; Egile, C.; et al. Phase I dose-escalation study of the PI3K/mTOR inhibitor voxtalisib (SAR245409, XL765) plus temozolomide with or without radiotherapy in patients with high-grade glioma. Neuro-Oncology 2015, 17, 1275-1283. [CrossRef] [PubMed]

15. Arvind, S.; Arivazhagan, A.; Santosh, V.; Chandramouli, B.A. Differential expression of a novel voltage gated potassium channel-Kv 1.5 in astrocytomas and its impact on prognosis in glioblastoma. Br. J. Neurosurg. 2012, 26, 16-20. [CrossRef] [PubMed]

16. Gheewala, T.; Skwor, T.; Munirathinam, G. Photosensitizers in Prostate cancer therapy. Oncotarget 2017, 8, 30524-30538. [CrossRef] [PubMed]

17. Shafirstein, G.; Bellnier, D.; Oakley, E.; Hamilton, S.; Potasek, M.; Beeson, K.; Parilov, E. Interstitial Photodynamic Therapy-A focused Review. Cancers 2017, 9, 12. [CrossRef] [PubMed]

18. Kawczyk-Krupka, A.; Wawrzyniec, K.; Musiol, S.K.; Potempa, M.; Bugaj, A.M.; Sieroń, A. Treatment of localized prostate cancer using WST-09 and WST-11 mediated vascular targeted photodynamic therapy-A review. Photodiagn. Photodyn. Ther. 2015, 12, 567-574. [CrossRef] [PubMed]

19. Moore, C.M.; Azzouzi, A.R.; Barret, E.; Villers, A.; Muir, G.H.; Barber, N.J.; Bott, S.; Trachtenberg, J.; Arumainayagam, N.; Gaillac, B.; et al. Determination of optimal drug dose and light dose index to achieve minimally invasive focal ablation of localised prostate cancer using WST11-vascular-targeted photodynamic (VTP) therapy. BJU Int. 2015, 116, 888-896. [CrossRef] [PubMed]

20. Bugaj, A.M. Vascular targeted photochemotherapy using padoporfin and padeliporfin as a method of the focal treatment of localised prostate cancer-clinician's insight. J. Photochem. Photobiol. World J. Methodol. 2016, 6, 65-76. [CrossRef] [PubMed]

21. Spring, B.Q.; Rizvi, I.; Xu, N.; Hasan, T. The role of photodynamic therapy in overcoming cancer drug resistance. Photochem. Photobiol. Sci. 2015, 14, 1476-1491. [CrossRef] [PubMed]

22. Pandey, R.K.; Kessel, D.; Dougherty, T.J. Handbook of Photodynamic Therapy: Updates on Recent Applications of Porphyrin-Based Compounds; World Scientific: Hackensack, NJ, USA, 2016.

23. Ascencio, M.; Collinet, P.; Farine, M.O.; Mordon, S. Protoporphyrin IX fluorescence photobleaching is a useful tool to predict the response of rat ovarian cancer following hexaminolevulinate photodynamic therapy. Lasers Surg. Med. 2008, 40, 332-341. [CrossRef] [PubMed] 
24. McIlroy, B.W.; Mann, T.S.; Dysart, J.S.; Wilson, B.C. The effects of oxygenation and photosensitizer substrate binding on the use of fluorescence photobleaching as a dose metric for photodynamic therapy. Vib. Spectrosc. 2002, 28, 25-35. [CrossRef]

25. Wilson, B.C.; Patterson, M.S.; Lilge, L. Implicit and explicit dosimetry in photodynamic therapy: A New paradigm. Lasers Med. Sci. 1997, 12, 182-199. [CrossRef] [PubMed]

26. Zhu, T.C.; Finlay, J.C. The role of photodynamic therapy (PDT) physics. Med. Phys. 2008, 35, 3127-3136. [CrossRef] [PubMed]

27. Patterson, M.S.; Madsen, S.J.; Wilson, B.C. Experimental tests of the feasibility of singlet oxygen luminescence monitoring in vivo during photodynamic therapy. J. Photochem. Photobiol. B Biol. 1990, 5, 69-84. [CrossRef]

28. Strekowski, L. (Ed.) Synthesis, Properties and Applications. In Heterocyclic Polymethine Dyes; Springer: Berlin, Germany, 2008.

29. James, N.S.; Chen, Y.; Joshi, P.; Ohulchanskyy, T.Y.; Ethirajan, M.; Henary, M.; Strekowsk, L.; Pandey, R.K. Evaluation of polymethine dyes as potential probes for near infrared fluorescence imaging of tumors: Part-I. Theranostics 2013, 3, 692-702. [CrossRef] [PubMed]

30. James, N.S.; Ohulchanskyy, T.Y.; Chen, Y.; Joshi, P.; Zheng, X.; Goswami, L.N.; Pandey, R.K. Comparative tumor imaging and PDT efficacy of HPPHconjugated in the mono- and di-forms to various polymethine cyanine dyes: Part-2. Theranostics 2013, 3, 703-718. [CrossRef] [PubMed]

31. Henderson, B.W.; Busch, T.M.; Snyder, J.W. Fluence rate as a modulator of PDT mechanisms. Lasers Surg. Med. 2006, 38, 489-493. [CrossRef] [PubMed]

32. Achilefu, S.; Bornhop, D.J.; Raghavachari, R. (Eds.) Molecular Probes for Biomedical Applications II. In Proceedings of the SPIE, San Jose, CA, USA, 21-22 January 2008.

33. Henderson, B.W.; Gollnick, S.O.; Snyder, J.W.; Busch, T.M.; Kousis, P.C.; Cheney, R.T.; Morgan, J. Choice of Oxygen-Conserving Treatment Regimen Determines the Inflammatory Response and Outcome of Photodynamic Therapy of Tumors. Cancer Res. 2004, 64, 2120-2126. [CrossRef] [PubMed]

34. Pogue, B.W.; Sheng, C.; Benevides, J.; Forcione, D.; Puricelli, B.; Nishioka, N.; Hasan, T. Protoporphyrin IX fluorescence photobleaching increases with the use of fractionated irradiation in the esophagus. J. Biomed. Opt. 2008, 13, 034009. [CrossRef] [PubMed]

35. Robinson, D.J.; de Bruijn, H.S.; van der Veen, N.; Stringer, M.R.; Brown, S.B.; Star, W.M. Fluorescence photobleaching of ALA-induced protoporphyrin IX during photodynamic therapy of normal hairless mouse skin: The effect of light dose and irradiance and the resulting biological effect. Photochem. Photobiol. 1998, 67, 140-149. [CrossRef] [PubMed]

36. Robinson, D.J.; de Bruijn, H.S.; van der Veen, N.; Stringer, M.R.; Brown, S.B.; Star, W.M. Protoporphyrin IX fluorescence photobleaching during ALA-mediated photodynamic therapy of UVB-induced tumors in hairless mouse skin. Photochem. Photobiol. 1999, 69, 61-70. [CrossRef] [PubMed]

37. Sheng, C.; Hoopes, P.J.; Hasan, T.; Pogue, B.W. Photobleaching-based dosimetry predicts deposited dose in ALA-PpIX PDT of rodent esophagus. Photochem. Photobiol. 2007, 83, 738-748. [CrossRef] [PubMed]

38. Van Veen, R.L.; Aalders, M.C.; Pasma, K.L.; Siersema, P.D.; Haringsma, J.; van de Vire, W.; Gabeler, E.E.; Robinson, D.J.; Sterenborg, H.J. In situ light dosimetry during photodynamic therapy of Barrett's esophagus with 5-aminolevulinic acid. Lasers Surg. Med. 2002, 31, 299-304. [CrossRef] [PubMed]

39. Patterson, M.S.; Wilson, B.C. Theoretical study of the influence of sensitizer photobleaching on depth of necrosis in photodynamic therapy. In Proceedings of the SPIE, Los Angeles, CA, USA, 3 November 1994; pp. 208-219.

40. Patterson, M.S.; Wilson, B.C.; Graff, R. In vivo tests of the concept of photodynamic threshold dose in normal rat liver photosensitized by aluminum chlorosulfonated phthalocyanine. Photochem. Photobiol. 1990, 51, 343-349. [CrossRef] [PubMed]

41. Wilson, B.C.; Weersink, R.A.; Lilge, L. Fluorescence in Photodynamic Therapy Dosimetry; Marcel Dekker, Inc.: New York, NY, USA, 2003; pp. 529-561.

Sample Availability: Samples of the compounds are not available from the authors. 